\title{
Abnormal Behavior
}

National Cancer Institute

\section{Source}

National Cancer Institute. Abnormal Behavior. NCI Thesaurus. Code C122430.

Conduct that is unusual for the individual. 